DOI: https://doi.org/10.30749/2594-8261.v1n1p164-174

\title{
RETRATO DE UMA LUANDA INVISÍVEL EM OS TRANSPARENTES, DE ONDJAKI ${ }^{1}$
}

PORTRAIT OF AN INVISIBLE LUANDA IN OS TRANSPARENTES, BY ONDJAKI

Renata Flavia da Silva ${ }^{2}$

Resumo: Em Os transparentes (2012), o escritor angolano Ondjaki apresenta a cidade de Luanda como, mais que uma indicação geográfica, uma construção simbólica capaz de refletir e problematizar a história recente de seu país. Paisagem contemporânea, marcada por profundas cicatrizes, a capital angolana é descrita em suas relações desiguais de ocupação do espaço urbano e de visibilidade social. Nessa paisagem irregular, onde a exceção se estabelece como regra, o apagamento do sujeito, sua progressiva invisibilidade, é a representação textual de um lugar onde o humano perde espaço para os valores materiais em uma sociedade cada vez mais objetivada. Pretende-se, portanto, no presente trabalho, analisar como o espaço narrativo recupera o processo histórico-cultural vivenciado pelos angolanos, constituindo, assim, uma linha de fuga em um horizonte de violência e caos.

Palavras-chave: Literatura angolana. Paisagem. (In)visibilidade.

Abstract: In Os transparentes (2012), the Angolan writer Ondjaki presents the city of Luanda as, more than a geographical indication, a symbolic construction capable of reflecting and problematizing the recent history of his country. Contemporary landscape, marked by deep scars, the Angolan capital is described in its unequal relations of occupation of urban space and social visibility. In this irregular landscape, where the exception is established as a rule, the erasing of the subject, its progressive invisibility, is the textual representation of a place where the human loses space for material values in an increasingly objectified society. The present work intends to analyze how the narrative space recovers the historical-cultural process experienced by Angolans, thus constituting a line of escape in a horizon of violence and chaos.

Keywords: Angolan literature. Landscape. (In)visibility.

\footnotetext{
1 Uma versão inicial deste texto foi apresentada durante o XXV Congresso Internacional da ABRAPLIP - Cartografias literárias em língua portuguesa: experiências estéticas e culturais no contexto global, realizado na Universidade do Estado do Amazonas, 2015.

${ }^{2}$ Vice-Coordenadora do Programa de Pós-Graduação em Estudos de Literatura. Prof ${ }^{\mathrm{a}}$. de Literaturas Africanas de Língua Portuguesa. Dept ${ }^{\circ}$. de Letras Clássicas e Vernáculas - GLC. Instituto de Letras IL - Universidade Federal Fluminense/UFF.
} 


\section{INTRODUÇÃO}

era um prédio, talvez um mundo,

para haver um mundo basta haver pessoas e emoções. as emoções, chovendo internamente no corpo das pessoas, desaguam em sonhos. as pessoas talvez não sejam mais do que sonhos ambulantes de emoções derretidas no sangue contido pelas peles dos nossos corpos tão humanos. a esse mundo pode chamar-se «vida».

$[\ldots]$

[das anotações do autor] (ONDJAKI, 2012, p. 75).

Como o título apresentado já anuncia, este texto falará de uma cidade, ou, se preferirem, da multiplicidade de horizontes em uma cidade, sua arquitetura, suas gentes. Uma cidade que se mostra e se esconde para se mostrar mais ainda, como um desenho em negativo ${ }^{3}$ o qual ressalta os contornos do objeto desenhado. A partir do romance Os transparentes, "um retrato poderoso da Luanda de hoje", segundo a capa da edição portuguesa, podemos apreender uma paisagem percebida pela sensibilidade do jovem autor angolano, o que nos leva à problematização de um processo cultural como questionamento da natureza histórica de um lugar.

\section{DESENVOLVIMENTO}

A cidade de Luanda sempre esteve presente no centro da paisagem literária angolana. Pesquisadoras como Rita Chaves e Tania Macêdo já o afirmavam desde longa data, ressaltando em seus estudos a prevalência do espaço urbano luandense na produção romanesca de Angola e sua apropriação como representação microtextual dos processos históricos vivenciados.

[...] Além do tempo, é preciso ganhar os espaços, apropriar-se de todo o território. Desse modo, sem se falar propriamente de um programa preestabelecido, o olhar atento sobre as produções permite detectar procedimentos que espelham a vontade de incorporar as terras em sua extensão, não obstante o ato de escrever se faça predominantemente da capital, onde tem vivido a maioria dos escritores. (CHAVES, 1999, p. 22)

\footnotetext{
${ }^{3}$ Denomina-se desenho em negativo a técnica mediante a qual se produz uma imagem a partir da criação de espaços a volta dela, como uma moldura.
} 
O que buscamos apresentar e discutir [...] são as formas de representação que a cidade de Luanda recebe na moderna literatura angolana, de maneira que se pode afirmar que esta cidade tornou-se emblema de um projeto de nação e de literatura (MACÊDO, 2008, p. 16).

Apesar de nos últimos anos termos um alargamento dos espaços abrangidos pela cena literária angolana, Ondjaki insiste, ainda, em Os transparentes, em ambientar sua narrativa na complexa capital, expondo suas novas configurações as quais extrapolam a dicotômica paisagem dos anos 50 e 60, dividida entre o asfalto e o musseque.

Antes de passarmos ao romance, devemos ressaltar que o termo "paisagem" possui várias acepções e abordagens diferenciadas. Partindo do conceito definido pelo ensaísta francês Michel Collot, adotamos o termo para referirmo-nos a um lugar simbólico, uma construção de sentido que envolve tanto o visível daquilo que é observado quanto o invisível (pres)sentido por quem observa. Sendo, deste modo, sujeito e objeto, quem olha e o quê olha, indissociáveis neste conjunto a que atribuímos o nome paisagem. Esta organização perceptiva favorece, através do olhar sobre objetos passados - quer sejam construções, ruínas, ou vazios - inseridos em uma perspectiva do presente, a compreensão da paisagem observada como uma história a ser contada. Recuperando o romance A caverna, de José Saramago, podemos dizer que é preciso "compreender que um caco no chão não é apenas o seu presente de caco no chão, é também o seu passado de quando não o era, é também o seu futuro de não saber o que virá a ser" (SARAMAGO, 2000, p. 182), uma paisagem em aberto.

Neste romance, publicado em 2012, Ondjaki nos apresenta a cidade de Luanda como, mais que uma indicação geográfica, uma construção simbólica capaz de refletir e problematizar a história recente de seu país. Paisagem contemporânea, marcada por profundas cicatrizes dos males sofridos ao longo dos anos, a capital angolana é descrita em suas relações desiguais de ocupação do espaço urbano e de visibilidade social. A principal construção arquitetônica observada, na narrativa, é um prédio em ruínas, uma paisagem precária que abriga diferentes personagens, tipos humanos carentes de um lugar do qual partam suas expectativas ou de um 
horizonte que as receba, pessoas em busca de sobrevivência em meio aos descaminhos da cidade de Luanda.

A obra aborda com poeticidade e agudo senso crítico a dura realidade do povo angolano, representada pela curiosa edificação e seus moradores. Entretanto, como um espaço negativo, o romance explora, também, outras extensões que cercam o prédio e sua variada população, descrita da seguinte forma, "Luanda fervia com a sua gente que vendia, que comprava para vender, que se vendia para ir depois comprar e gente que se vendia sem voltar a conseguir comprar (ONDJAKI, 2012, p. 72). Nesse cenário, pessoas comuns, habitações precárias, prédios de alto luxo, casas imponentes, ministros, empresários, cientistas, embaralham-se num labirinto cujo centro é o prédio, como uma força viva, capaz de agregar, de confrontar e proteger. Lembrando a pesquisadora argentina Beatriz Sarlo, devemos estar atentos ao fato de que "a pluralidade de ofertas não compensa a pobreza dos ideais coletivos" (SARLO, 2000, p. 09), e é justamente, essa carência de ideais capazes de assegurar o futuro desses indivíduos que o autor busca evidenciar. É a falta de utopias, o (ab)uso da moral e as tentativas de sobrevivência que proliferam na narrativa.

Nessa paisagem irregular, onde a exceção se estabelece como regra, o apagamento do sujeito, sua progressiva invisibilidade, é a representação textual de um lugar onde o humano perde espaço para os valores materiais em uma sociedade cada vez mais objetivada. As partes visíveis e invisíveis da cidade de Luanda integram a trama romanesca, a qual se apoia na paisagem descrita, para atribuir novos sentidos às memórias, quer físicas quer discursivas, perspectivadas pelas diferentes personagens. Pretende-se, portanto, no presente trabalho, apresentar como o espaço narrativo do romance em questão, humanizado pelo conceito de paisagem, retrata o processo histórico-cultural vivenciado pelos angolanos, constituindo, assim, uma linha de fuga em um horizonte marcado pela impossibilidade. A inusitada transparência da personagem pode ser lida como uma estratégia narrativa para fazer ver a marginalidade a que tantos estão submetidos.

-mas é que eu estava farto de comer de mão amiga, queria comer da mão do meu governo, mas não como os governantes 
comem, queria comer com o fruto do meu trabalho, da minha profissão [...]

- fui comendo cada vez menos para que os meus filhos pudessem comer o pouco que eu não comia, e foi assim [...]

-tive dores, no início, fome, dor de estômago, mas por alguma razão tive o instinto de não comer mais, era uma espécie de desistência, [...]

—até o dia em que as mãos começaram a ficar transparentes

[...] a transparência é um símbolo. e eu amo esta cidade ao ponto de fazer tudo por ela. chegou a minha vez, não podia recusar

[...] um homem pode ser um povo, a sua imagem pode ser a do povo... (ONDJAKI, 2012, p. 282-283).

A narrativa de Os transparentes tem início com a agonia da cidade, o grande incêndio que percorre os túneis escavados para extração de petróleo, como se fossem veias sob a pele da urbe e explode em grandes feridas que atingem a população, envolvendo a todos num retrato caótico de sofrimento e dor.

— ainda me diz qual é a cor desse fogo...

O Cego falou em direção à mão do miúdo que lhe segurava o corpo pelo braço, os dois num medo de estarem quietos para não serem engolidos pelas enormes línguas de fogo que saíam do chão a perseguir o céu de Luanda (ONDJAKI, 2012, p. 11).

Começando do fim, a narrativa parte de uma cena congelada, o incêndio, e retrocede ao início das escavações e dos caminhos percorridos pelas personagens a fim de reorganizar a cena -inicial e, simultaneamente, final —, atribuindo-lhe um sentido outro, o de libertação que se sobrepõe à ideia da morte iminente causada pelo fogo.

Apesar da dramaticidade contida no enredo, a narrativa mantém a leveza característica das obras do autor, a delicadeza das formas poéticas inseridas no discurso romanesco, quer na forma de epígrafes que introduzem os capítulos, quer nas palavras simples das personagens, suavizam a crueza da vida precária, a banalização da morte e a escassez de horizontes denunciados ao longo da obra. A presença da infância, traço recorrente na escrita do autor, marca, mais uma vez, um território seguro, capaz de fazer suportar os dramas vividos pelas personagens, como se verifica no trecho destacado a seguir: 
o miúdo puxou de dentro de si umas lágrimas quentes que o levassem até à infância porque era aí, nesse reino desprevenido de pensamentos, que uma resposta florida poderia nascer, viva e fiel ao que via (...) mais velho, estou a esperar uma voz de criança para lhe dar resposta" (ONDJAKI, 2012, p. 12).

Em meio ao calor do momento, é na memória dos tempos de infância que a personagem busca a resposta capaz de aplacar a angústia do mais-velho, o Cego, sua inquietação sobre qual a cor da luz quente que os envolvia, qual a cor do fogo que consumia tudo a seu redor.

É na paisagem em chamas que a narrativa expõe a questão fundamental do romance: a visibilidade do sujeito na contemporaneidade angolana, que lugar ocupa o indivíduo neste cenário em transformação, neste espaço em ruínas. Pensando o termo paisagem não apenas como um cenário urbano, mas, sobretudo, humano, observa-se, com mais precisão, o lugar simbólico ocupado pelo prédio, uma construção de sentido que, visualmente, congrega essa paisagem irregular que a perspectiva do presente permite observar, uma paisagem que simboliza a história do homem angolano. A consciência dos tempos após a independência, as dificuldades sobrepostas às necessidades de (re)construção do país, manifesta-se através da consciência do espaço, com tudo que lhe envolve. Deste modo, o horizonte descrito por Ondjaki, na narrativa, explora uma nova organização perceptiva do espaço angolano, na qual o apagamento do sujeito, sua progressiva invisibilidade, metaforizada na figura da personagem Odonato, é a representação textual de um lugar onde o humano perde espaço num cenário cada vez mais objetivado e objetivante:

Acanhados raios solares, de magreza extremada, fiapos tristes da cor amarela, atravessaram Odonato nas zonas periféricas do seu corpo esguio, nos rebordos da cintura, nos joelhos, também nas costas das mãos e nos ombros, a luz longínqua passava como se um corpo humano, real e sanguíneo, pudesse assemelhar-se a uma peneira ambulante (ONDJAKI, 2012, p. 34).

A personagem passa a ficar transparente, tal como as mazelas da cidade são transparentes aos olhos daqueles que poderiam fazer algo para melhorar a situação do povo, porém não enxergam tal condição, segundo a personagem, "一a 
verdade é ainda mais triste (...) não somos transparentes por não comer... nós somos transparentes porque somos pobres" (ONDJAKI, 2012, p. 203). A dura revelação feita pelo marido à mulher, sua estranha condição, é compartilhada pela narrativa que revela aos leitores a estranha condição de Angola independente, a visão do corpo de Odonato é também a visão do corpo da cidade, e, por extensão, do país, a visão da sua dor invisível aos olhos dos que veem o luxo e as riquezas como único horizonte.

As partes visíveis e invisíveis da cidade de Luanda formam a mesma paisagem, unindo os espaços socialmente distintos em uma perspectiva reflexiva e questionadora baseada nas memórias, quer físicas, das ruas ou construções, quer discursivas, recuperadas pelas diferentes personagens, e, ao mesmo tempo, retratando o processo histórico-cultural vivenciado pelos angolanos. A saudade do passado é um sentimento comum às personagens, sofrem de saudades de outros tempos, tempos também de escassez, de conflitos, porém mais generosos e felizes em oposição ao vazio, ao deserto de sentimentos no qual a cidade se transformou:

os seus olhos e o seu corpo sentiam profunda saudade dos passeios domingueiros com a família, para perto do mar, [...]

Luanda era então, se comparada com a atualidade, um quase deserto urbano onde faltava comida e a roupa, os medicamentos, sem água ou luz, [...] as festas pobres serviam para rever familiares e vizinhos do que para comer ou cometer exibicionismos de novo riquismo, o mar era mais generoso em peixe 180).

e até as pessoas eram mais brandas (ONDJAKI, 2012, p. 179-

Referências literárias do passado angolano também são recuperadas nostalgicamente na narrativa, como paisagens antigas de fotos amareladas, como ilustram os trechos a seguir, alusões claras às obras de Luandino Vieira:

Odonato viu-se de peito revolto a sentir claras saudades de uma Luanda que ali havia sem já haver, talvez o tempo se sobrepunha para o fazer sofrer, os pássaros de um antigo Kinaxixe com trejeitos de Makulusu cantavam invisíveis no seu ouvido semitransparente,

era ele que falava com a cidade ou era a cidade de Loanda, Luanda, Luuanda, que brincava de namorar com ele? (ONDJAKI, 2012, p. 182). 
ou ainda, às palavras de Agostinho Neto musicadas por Ruy Mingas:

o Carteiro abriu os olhos e caminhou em direção ao quinto andar onde um polido disco de vinil emitia a voz de Ruy Mingas entoando, dolente, uma canção que o Carteiro não ouvia há anos

minha mãe, tu me ensinaste a esperar, como esperaste paciente, nas horas difíceis ${ }^{4}$ (ONDJAKI, 2012, p. 216).

A história nacional evocada a partir de outros textos literários reforçam a atmosfera crescente de insatisfação, a espera ainda não terminou e a crença em dias melhores vacila ante a visão dos "bairros de pretos", "com fome" e "com sede" (ONDJAKI, 2012, p. 216), aqueles mesmos bairros pobres dos versos de Agostinho Neto recuperados, na narrativa, pela audição da canção de Ruy Mingas, visão esta que se sobressai a partir do retrato feito do prédio em ruínas. A construção, assim como seus moradores, mantém os traços do passado mas já apresenta os sinais do tempo, a corrosão, o desgaste, o sub, ou em alguns momentos, o super aproveitamento de seus interiores.

o Prédio tinha sete andares e respirava como uma entidade viva

havia que saber os seus segredos, as características úteis ou desagradáveis das suas aragens, o funcionamento dos seus canos antigos, os degraus e as portas que não davam para lugar algum. [...]

no $1^{\circ}$ andar, os canos rebentados e uma tremenda escuridão desencorajavam os distraídos e os intrusos

a água abundava, incessante, e servia a finalidades múltiplas, dali saía a água para o prédio todo, o negócio de venda por balde, lavagem de roupa e viaturas, (ONDJAKI, 2012, p. 16).

Entretanto, apesar de toda atmosfera de degradação física e humana, a paisagem revela, também, sinais de transformação, de recuperação dos espaços e dos indivíduos, as águas que escapam dos encanamentos e jorram no primeiro andar do edifício serão também águas salvadoras frente ao avanço do fogo e da destruição que assalta a cidade. Uma das muitas formas com que a capacidade de

\footnotetext{
${ }^{4}$ Os versos citados pertencem ao poema "Adeus à hora da largada", de Agostinho Neto, incluído na obra Sagrada esperança (Luanda: UEA, 1986), e gravado pelo cantor Ruy Mingas com o título "Adeus à hora da partida", no álbum Temas angolanos (CDA, 1974).
} 
superação do povo angolano é abordada na narrativa, sem que com isso se minimizem os sofrimentos de grande parte da população nem se corroborem estereótipos ou mitificações acerca das reais condições de vida do povo angolano.

\section{CONCLUSÃO}

A personagem que empresta seu corpo para que a cidade seja vista a partir de outra perspectiva, mais transparente, é a mesma que se eleva para poder ver, sob novos ângulos, aquilo que de perto é banalizado pela proximidade. Odonato, com o passar dos dias e ao perder sua consistência física, vai ficando cada vez mais leve, menos preso ao chão e àquilo que o aflige. Diante do incêndio que toma conta da cidade inteira, é no alto que se liberta do peso de seus dias e vislumbra novos horizontes: "subia um corpo leve afastando-se finalmente das pontas perigosas do fogo" (ONDJAKI, 2012, p. 423), constituindo, assim, uma linha de fuga no horizonte caótico da urbe. Recuperando, aqui, as propostas elaboradas por Ítalo Calvino para o milênio que hoje se vivencia, é na elevação do olhar que se torna possível considerar a paisagem sob outra ótica, outra lógica (menos capitalista, talvez), capaz de ressignificar as relações estabelecidas ao longo da história. Trata-se, portanto, de uma busca da leveza, pela narrativa, como reação ao peso do viver, lembrando, ainda, as palavras de Calvino, "a privação sofrida se transforma em leveza e permite voar ao reino em que todas as necessidades serão recompensadas" (CALVINO, 1990, p. 41). Voltando ao romance, do alto "a cidade era mais simples vista dali. sentia-se menos na pele e nos olhos o peso doloroso dos seus problemas, dos seus dramas" (ONDJAKI, 2012, p. 53).

Entretanto, tal deslocamento não pode ser encarado apenas como fuga ou uma desistência de encarar a dura visão que se coloca diante dos olhos; é, sobretudo, um distanciamento necessário para se ampliar os campos de visão e observar, em conjunto, na dimensão expandida do olhar, a paisagem como um objeto cultural. Para a personagem, passaram-se muitos anos em que a busca da beleza fazia com que suportassem a feiura e a crueza dos horizontes, mas já é chegado o tempo de se encarar o que não está bem, sem disfarces, sem obstáculos à visão, ainda que seja seu próprio corpo. 
O prédio e Odonato, corpos em ruínas, vistos a partir de seus interiores são metáforas da nação, de uma nação que atingida duramente pelo tempo, sem cuidado e sem reparo, sobrevive e espera por dias melhores. A paisagem urbana, caótica, humanizada com a presença de personagens comuns, pessoas comuns que têm suas vidas desafiadas diariamente e que compõem a enorme massa de indivíduos "transparentes" aos olhos de muitos, retrata com maestria a contemporaneidade da nação africana em tempos de globalização. Enfim, trata-se de um romance de grande fôlego, em meio à fumaça dos incêndios que se vislumbram no cotidiano, e densidade, apesar da transparência reiterada pela personagem, uma narrativa dramática sem, contudo, perder a delicadeza imaginativa nem a poeticidade, já conhecidas do público.

Era um prédio, com suas pessoas, seus sonhos, era a "vida" na Luanda dos dias de hoje, era o espaço narrativo como uma experiência temporal, capaz de reorganizar a leitura do passado e do presente. Era a leveza de Odonato capaz de unir a terra e céu, como uma passagem do real ao possível, a um futuro possível. E encerro com as palavras do autor, voltando ao princípio:

era um prédio, talvez um mundo,

para haver um mundo basta haver pessoas e emoções. as emoções, chovendo internamente no corpo das pessoas, desaguam em sonhos. as pessoas talvez não sejam mais do que sonhos ambulantes de emoções derretidas no sangue contido pelas redes de nossos corpos tão humanos. a esse mundo pode chamar-se 'vida'. (ONDJAKI, 2012, p. 75).

\section{REFERÊNCIAS}

CALVINO, Ítalo. Seis propostas para o próximo milênio. Tradução Ivo Barroso. São Paulo: Companhia das Letras, 1990.

CHAVES, RITA. A formação do romance angolano: entre intenções e gestos. São Paulo: USP, Via Atlântica, 1999.

COLLOT, Michael. De l'horizon du paysage à l'horizon des poètes (Do horizonte da paisagem ao horizonte dos poetas). Trad. Eva Nunes Chatel. In: ALVES, Ida Ferreira; FEITOSA, Marcia Manir Miguel (Org.). Leitura e paisagem: perspectivas e diálogos. Niterói: EdUFF, 2010. 
MACÊDO, Tania. Luanda, cidade e literatura. São Paulo: Editora UNESP; Luanda: Nzila, 2008.

ONDJAKI. Os transparentes. Alfragide: Editorial Caminho, 2012.

SARAMAGO, José. A caverna. São Paulo: Companhia das Letras, 2000.

SARLO, Beatriz. Cenas da vida pós-moderna: intelectuais, arte e videocultura na Argentina. Tradução Sérgio Alcides. 2. ed. Rio de Janeiro: UFRJ, 2000. 